University of Wollongong

Research Online

Faculty of Business - Papers (Archive)

Faculty of Business and Law

2013

Quality of life and tourism: a conceptual framework and novel segmentation base

Sara Dolnicar

University of Wollongong, s.dolnicar@uq.edu.au

Katie Lazarevski

University of Wollongong, katiel@uow.edu.au

Venkata Yanamandram

University of Wollongong, venkaty@uow.edu.au

Follow this and additional works at: https://ro.uow.edu.au/buspapers

Part of the Business Commons

Research Online is the open access institutional repository for the University of Wollongong. For further information contact the UOW Library: research-pubs@uow.edu.au 


\title{
Quality of life and tourism: a conceptual framework and novel segmentation base
}

\begin{abstract}
The present study (1) develops a dynamic, individual hierarchical model of the importance of vacations to Quality of Life (QOL), and (2) introduces this concept as a novel segmentation base, acknowledging that not all people want to go on vacation. The proposed Grevillea Model of the Importance of Vacations for Quality of Life is tested empirically by examining 1000 survey responses. Results show that $10 \%$ of Australians perceive vacations as critical to QOL. Another $60 \%$ perceive vacations add to, but they are not essential to QOL. Practical tourism marketing implications include: (1) vacations are not important to all people; therefore, mass marketing is a waste of resources, (2) people viewing vacations as essential to QOL represent a highly attractive market segment because they are likely to be crisis-resistant, and (3) a vacation's importance to QOL changes over life-stages.
\end{abstract}

\section{Keywords}

conceptual, framework, novel, segmentation, base, quality, life, tourism

Disciplines

Business

\section{Publication Details}

Dolnicar, S., Lazarevski, K. \& Yanamandram, V. (2013). Quality of life and tourism: a conceptual framework and novel segmentation base. Journal of Business Research, 66 (6), 724-729. 


\title{
Quality of life and tourism:
}

a conceptual framework and novel segmentation base

\author{
Sara Dolnicar* \\ University of Wollongong \\ Katie Lazarevski* \\ University of Wollongong \\ Venkata Yanamandram* \\ University of Wollongong
}

Send correspondence to Sara Dolnicar, Institute for Innovation in Business and Social Research (IIBSoR), School of Management and Marketing, University of Wollongong,

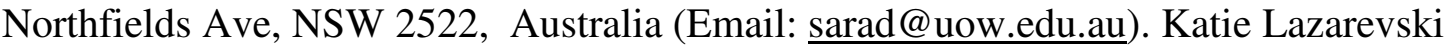
(Email: k167@uow.edu.au), Venkata Yanamandram (Email: venkaty@uow.edu.au).

*Authors listed in alphabetical order. 


\begin{abstract}
The present study (1) develops a dynamic, individual hierarchical model of the importance of vacations to Quality of Life (QOL), and (2) introduces this concept as a novel segmentation base, acknowledging that not all people want to go on vacation. The proposed Grevillea Model of the Importance of Vacations for Quality of Life is tested empirically by examining 1,000 survey responses. Results show 10 percent of Australians perceive vacations as critical to QOL. Another 60 percent perceive vacations add to, but they are not essential to QOL. Practical tourism marketing implications include: (1) vacations are not important to all people; therefore, mass marketing is a waste of resources, (2) people viewing vacations as essential to QOL represent a highly attractive market segment because they are likely to be crisis-resistant, and (3) a vacation's importance to QOL changes over life-stages.
\end{abstract} Keywords: Quality of Life, Market Segmentation, Vacations, Travel Motivations. 
Tourists differ in their travel motivations, travel companions, activities, and many other characteristics. Ignoring these differences and creating one undifferentiated destination marketing mix satisfies few people. Tourism destination managers need to effectively allocate resources in targeting market segments they can serve best. Market segmentation allows some degree of customization to help create a competitive advantage (Dolnicar, 2008). Additionally, segmentation increases resource efficiency by only targeting tourists likely interested in what the destination offers.

There are various methods to segment tourist markets, because no single best way exists to group tourists (Kotler, Armstrong, Brown, and Adam, 1998). Broadly classified approaches include a priori (Mazanec, 2000) or commonsense (Dolnicar, 2004) segmentation or post-hoc (Myers and Tauber, 1977), a posteriori (Mazanec, 2000), or data-driven segmentation (Dolnicar, 2004).

The typical variables employed in commonsense segmentation tourism studies include demographics (Collins and Tisdell, 2002; Kim, Lehto, and Morrison, 2007), geographic criteria (Juaneda and Sastre, 1999; Reid and Reid, 1997), usage levels (Goldsmith and Litvin, 1999), visitation (Baloglu and McCleary, 1999), and intention (Hsu and Crotts, 2006). Tourism's data-driven segmentation studies include variables such as travel motivations (Bieger and Laesser, 2002; de Guzman, Leones, Tapia, Wong, and de Castro, 2006; Shoemaker, 2000), travel benefits (Frochot, 2005; Molera and Albaladejo, 2007; Sarigollu and Huang, 2005), information sources (Bieger and Laesser, 2004; Fodness and Murray, 1997), vacation activities (Becken and Gnoth, 2004; Dolnicar and Leisch, 2004; Sung, 2004; Taylor and Prideaux, 2008), values (Muller, 1991; Pizam and Calatone, 1987), destination image (Dolnicar and Huybers, 2007; Leisen, 2001), emotions (Bigne and Andreu, 2004; Chen, 2003), personality (Frew and Shaw, 1999), and self concept (Todd, 2001). 
Any market segmentation study's value to managers depends less on the methodology than whether or not a segmentation solution is meaningful and useful for marketing action (Dolnicar and Lazarevski, 2009). Correctly identifying the market segment helps sustain a destination's competitive advantage. As illustrated above, many segmentation methods exist. These segmentation strategies assume the people traveling desire to take the trip. Does everyone on vacation really want to travel? This paper argues market segmentation should consider the possibility that some people are accidental tourists-they may not want to travel. For these travelers, the trip serves another purpose. This study focuses on how vacations affect a person's overall Quality of Life (QOL) and proposes a method to identify people for whom vacationing is a necessary activity.

The newly proposed segmentation base represents a significant innovation for tourism market segmentation. QOL segmentation offers three major advantages over segmentation bases currently used in tourism segmentation studies.

QOL acknowledges not all people want to go on vacations. People assign varying importance to the different aspects that determine their personal QOL (Scalon, 1993). Some people see family as the most important contributor to QOL, while others view their work to be the key driver. In the same way, some people perceive vacations as absolutely necessary for maintaining a certain QOL, while others view taking vacations as a way to enhance QOL, although they would be just as satisfied if taking vacations were not possible. Some people may not care about vacations at all. The different values people place on vacation-taking indicates heterogeneity in the population, thus creating opportunities for tourism marketers.

QOL identifies crisis-resistant tourists. External events such as the global financial crisis impacts disposable incomes and reduce travel volume. Because maintaining a certain level of QOL is essential to people (Dunbar, Stoker, Hodges, and Beaumont, 1992), people 
requiring vacations to maintain their QOL will continue taking vacations, regardless of impediments.

QOL's theoretical foundation is strong. Segmentation algorithms (e.g., cluster analysis) are exploratory exercises; however, the construct of QOL is theory-based. Theory is "a set of interrelated constructs (concepts), definitions, and propositions that present a systematic view of phenomena by specifying relations among variables, with the purpose of explaining and predicting phenomena" (Kerlinger, 1973, p. 9). Most segmentation studies use segmentation bases without a theoretical foundation (e.g., activity-based segmentation). QOL is based on psychological theory (see Section 2 below). Previous QOL studies inform the model proposed for measuring what segments of the population are the best target markets for tourism destinations and managers.

The present study contributes to the tourism marketing literature in the following ways:

(1) Proposes a dynamic, three-step hierarchical model of the contribution vacations can make to a person's QOL (the Grevillea Model of the Importance of Vacations for Quality of Life) and a measurement approach reflecting the hierarchical model;

(2) Introduces the QOL construct as a novel segmentation base in tourism. We construct tourist market segments based on differences in the contribution vacations make to their QOL. Segments for which vacations are important are particularly attractive for tourism destinations and businesses.

(3) Tests empirically the usefulness of the proposed segmentation base; and

(4) Identifies market segment profiles which attribute different importance to vacations in contributing to their QOL. These profiles show tourism managers the practical usefulness of considering QOL domains as a segmentation base.

QOL segmentation has major practical implications. If QOL affects vacation decision making, mass marketing's efficiency seems ineffective for destination marketing. Market 
segments viewing vacations as absolutely essential to QOL may represent the most crisis resistant and thus managerially attractive segments. Segments not feeling vacations contribute to their QOL represent misallocations of marketing dollars.

\section{Literature review}

\subsection{Quality of life: definition and measurement}

QOL usually means a person's sense of well-being, satisfaction or dissatisfaction with life, or happiness or unhappiness (Dalkey and Rourke, 1973). The QOL construct first emerged in the 1960s, many years after Maslow's (1962) hierarchy of needs. Although competing views about the relationship between QOL and needs satisfaction are documented (e.g., Haas, 1999), the former generally refers to evaluating the general well-being of individuals and societies (Derek et al., 2009) with key well-being indicators of life satisfaction (Ryff and Keyes, 1995). This view corroborates mainstream psychology's definition of QOL as a "conscious cognitive judgement of satisfaction with one's life"operationalized either uni-dimensionally or multi-dimensionally in terms of overall life satisfaction, or specific domains considered separately (Rejeski and Mihalko, 2001, p.23). Other authors assume overall life satisfaction functionally relates to happiness within many individual life domains (e.g., Lee and Sirgy, 1995).

\subsection{Vacations, quality of life, and heterogeneity}

How do vacations affect people's QOL? A review of 14 QOL measures finds most include Work, Material well-being, and Health; nearly two-thirds view Leisure and recreation as contributing to QOL (Cummins, McCabe, Romeo, and Gullone, 1994; Dazord, Gerin, and Boissel, 1994); Dunbar, Stoker, Hodges, and Beaumont, 1992; Ferrans and Powers, 1985; Flanagan, 1978; Frisch, 1994; Gall and Evans , 2000; Johnston, 1988; Kreitler 
and Kreitler, 2006; Lance, Mallard, and Michalos 1995; Lazim and Osman, 2009; Lever, 2000; Neal, Sirgy, and Uysal, 2004; Olson and Barnes, 1992). Vacations, as a separate domain, constitute about one-fourth of the test batteries reviewed. Thus, while Leisure and recreation generally is accepted as a QOL domain, Vacations rarely stand alone as a domain. Vacations tend to be covered implicitly by the Leisure and recreation domain-masking their contribution as leisure time away from home and preventing the understanding of their QOL role. Vacations are an integral feature of modern life for many people in industrialized nations and represent a possible avenue for individuals to pursue life satisfaction (Rubenstein, 1980). Vacations play a triple role in contributing to QOL by providing: (1) physical and mental rest and relaxation; (2) personal development space and the pursuit of personal and social interests; and (3) symbolic consumption to enhance status (Richards, 1999).

One research stream separates vacation's contribution to QOL from home-based leisure activities. Neal, Sirgy and Uysal $(1999,2004)$ pioneer this line of research. Neal et al. (1999) study visitor's satisfaction with travel and tourism experiences in the overall QOL context, predominantly focusing on service evaluations and satisfaction. They conclude service and experience satisfaction, trip reflections, and satisfaction with service aspects of tourism phases and non-leisure life domains affect overall satisfaction with life (Neal et al., 2004).

Sirgy, Kruger, Lee and Yu (2010) investigate how positive and negative trip experiences affect overall well-being. Their model illustrates the connections between trip experiences, satisfaction with life domains, and overall satisfaction with life. Investigating market structure and subjective well-being's influence, Sirgy (2010) demonstrates goal achievement's importance, and not just satisfaction with tourism services. Gilbert and Abdullah (2004) investigate whether vacationing impacts life satisfaction or well-being. Their comparison of a holiday-taking group and a non-holiday-taking group finds that vacationers experience a higher sense of well-being than non-vacationers. Javalgi, Thomas 
and Rao (1992) attribute pleasure travel as an important aspect of Korean senior's QOL. Similarly, Lee and Tideswell (2005) find vacation travel improves QOL for senior citizens and creates new interests in their lives.

Incorporating a standardized set of domains into QOL definitions is criticized (e.g., Keith, 2001), largely because researchers acknowledge that they are not be equally important to all people. For example, Murray (1938) argues the strength of various needs differs from person to person. Gratton (1980) also finds that some domains are intrinsically more important to QOL than others, to both individuals and particular groups. As a consequence, many psychological measures (e.g., Frisch et al., 1992) ask people to state each domain's importance to them. This approach implies specific domains are not equally important to all people. Based on these findings, the contribution vacations make to QOL varies and becomes a very attractive segmentation base for tourism, and highlights that no single, rigid model of domain importance in QOL can be developed.

The current study proposes that when identifying domains contributing to QOL constructs, researchers also should consider the hierarchy of needs varies across, and within, individuals over time. Models ranking domain importance should weigh domain satisfaction by the importance a person attributes to the specific domain. This paper extends the QOL literature by focusing on the domain of Vacations. The proposed Grevillea Model of the Importance of Vacations for Quality of Life is a dynamic, individual, and hierarchical model demonstrating the role vacations play in people's lives at any given point in time.

\section{The Grevillea model of the importance of vacations for quality of life}

Grevilleas are Australian native flowers. The Grevillea metaphor visually demonstrates how domains work within the QOL construct. The Grevillea's stock represents the core domains of Quality of Life for people. Without the stock, the Grevillea cannot live. Similarly, 
core domains are defined in the Grevillea Model as essential domains for a person-areas without compromise.

Grevilleas also are known for their spectacular flowers. Grevilleas do not need the flowers to survive, but flowering Grevillea take the plant from surviving to thriving. In the same way, enhancement domains take people to a higher life quality. People do not need enhancement domains for survival; they do not reflect the most essential, important domains. If present, enhancement domains further improve a person's QOL - they can make a person bloom.

The Grevillea Model also acknowledges that QOL is an individual rather than a general concept. What determines a good QOL for one person, may not determine the same QOL for another person. Consequently, one person's core domain may only be an enhancement domain for another. Like the hundreds of Grevillea varieties, people rate differently the importance of various QOL domains. Individual differences extend even further when one considers that each domain contributes differently to an individual's overall life satisfaction.

Finally, the Grevillea Model acknowledges QOL is dynamic. "Grevilleas mostly flower from late winter into spring, but there are a number of species which you will find adding color to the hot summer" (Greengold Garden Concepts, 2006). Like Grevilleas, people experience seasons of life. Vacations may be a core domain in the worry-free twenties, but they may later become an enhancement domain when mortgage repayments and family responsibilities move up in priority.

The Grevillea Model follows traditional behavioral theories such as Maslow's (1962) hierarchy of needs by acknowledging some needs (or domains) are more important than others. The Grevillea Model differs from Maslow because no general hierarchy is proposed. Instead, the Model acknowledges that the importance of needs (or domains) vary across individuals, and within individuals, over time. The Model also suggests QOL consists of 
several domains varying in importance to different people. Grevillea aligns QOL measurements, weighing people's satisfaction with domains by the importance they attribute to each one.

\section{Figure 1 here}

The Grevillea Model proposes a structure of what QOL means to different people. Actual QOL levels are determined by the particular structure and the extent each person rates components.

\section{Methodology}

\subsection{Fieldwork administration}

Data were collected in January 2010 using a questionnaire sent out to members of a permission-based internet panel. A total of 1,000 responses were collected. The online collection allows quick data collection, a customized format, and an easy instrument for respondents to complete. Sample representativeness was not essential because the study aims to identify the extent to which vacations contribute to people's QOL as a useful segmentation base. Determining segment size within the population is beyond this study's scope.

\subsection{Measurement}

This paper takes a disaggregate, subjective well-being approach focusing on “individuals' subjective experience of their lives” (Diener and Suh, 1997, p. 191); that is, their "own internal judgment of well-being" (p. 201) as opposed to using aggregate social indicators. This approach is consistent with Campbell et al.'s (1976) conclusion that the subjective perception of well-being is not necessarily associated with objective criteria typically included in social indicator QOL measures. A novel measure specifically reflects the proposed Grevillea model. 
The questionnaire design was informed by (1) a review of test batteries measuring QOL in healthy adults, and (2) a series of interviews with a heterogeneous, convenience sample of respondents. From these two information sources, the study derived domains viewed as contributing to people's QOL, either by the authors of test batteries or by respondents from the qualitative study phase.

Respondents were asked to use a Grevillea metaphor describing the impact of certain areas of life. By dragging an item onto the Grevillea's stock, the respondent indicates the item is a core QOL domain. Likewise, items dragged onto the flower indicate the enhancement domain; items dragged onto a space next to the Grevillea suggest the domain does not impact respondent's QOL.

A further question required respondents to categorize a condensed list of eight QOL domains in order of importance. The eight domains include family, work, people (not family), leisure, money, health, vacation, and spiritual life. To gain insight into how much each domain affects QOL, respondents assigned percentage points to each domain to reflect each item's effect. The assigned points had to add up to 100 percent.

Respondents provided socio-demographic questions, namely age, gender, geographic state of residence, nationality, income, marital status, education level. Also, respondents answered questions about travel-related behaviors, including the number of long vacations taken over the last 12 months, the number of short vacations taken over the last 12 months, their optimal number of short vacations, and whether they felt the number of vacations they took was enough. Long vacations were defined as "away from home for a week or longer" and short vacations were defined as "weekends or long weekends spent away from home" (excluding weekends spent at a partner's house). The questionnaire was pretested with five people, who were asked to talk aloud while they completed the self-administered questionnaire. 


\subsection{Data analysis}

An a priori or commonsense segmentation study was conducted by separating respondents into three groups: those who dragged the Vacations item onto the Grevillea's stem, indicating that vacations are core to their QOL; those who dragged the Vacations item onto the Grevillea's flower, indicating that vacations enhance their QOL; and those who dragged the Vacations item onto the grass next to the Grevillea, suggesting that vacations do not affect their QOL.

A priori segmentation helps understand differences in travel-related decision making (Sirakaya and Woodside, 2005) and is preferable to more complex segmentation methods if suited to the research problem. A priori segmentation represents the simplest possible model of analysis for this research.

\section{Results}

In this sample of Australian adults, 11 percent (108 respondents) stated that vacations are core to their QOL, 59 percent (590 respondents) stated that vacations are not essential, but they potentially enhance their QOL. About 30 percent (302 respondents) indicated vacations do not contribute to their QOL. These three a priori segments are sufficiently sized to develop profiles of each group's characteristics. Table 1 shows three a priori group profiles. The resulting three a priori segments can be described as follows.

Segment one does not believe vacations are important. Overall, this segment's members have the lowest QOL; they neither feel good about their life, nor do they believe they have a fulfilling life. Members of this segment do not feel a need for short or long vacations, and their optimal number of vacations away is less than the other two segments. This segment includes a higher proportion of part-time workers, housewives/husbands, and unemployed 
persons. Segment one has the lowest income of the three segments. Segment one members believe health and spiritual life affect their QOL most. This segment's inspiration to travel derives from needs to develop themselves and their self-esteem and to gain social recognition. However, Segment one members do not value travel and they are not attractive from destination management's point of view. Motivating this segment to travel is difficult if they do not believe the trip contributes to their QOL. Furthermore, a majority of this segment feels they have had enough long and short vacations. In Table 1, the icon is associated to the Segment one profile data is an image of grass. Grass illustrates the association to other features surrounding the Grevillea plant. Grass metaphorically describes areas surrounding people's lives not directly impacting QOL.

\section{Table 1 here}

Segment two believes vacations enhance their QOL. This segment's QOL is reasonably high; they generally feel good about their life and have the highest agreement with the statement "I lead a meaningful and fulfilling life". One-third of this segment feels that they do not take enough short or long vacations last year. Their frequency of short vacations is higher than Segment one. This segment has the highest proportion of full time employees and earns mid-level incomes. Segment two values vacations more than Segment one. They also place an importance on leisure and spiritual life. Motivations for travel include experiencing something new and having fun. Destination managers find this segment more attractive because travel leads to enhancing QOL. Most Segment two respondents feel they do not take enough vacations. Promotional messages motivating this segment to travel include encouraging people to escape from their busy workloads. The icon of the Grevillea flower accompanying the profile data in Table 1 signifies this segment believes vacations enhance their QOL; much like a Grevillea's bloom enhances the plant's overall appearance. 
Segment three believes travel is important for QOL. They attributed the highest amount of importance points to vacations and leisure. This segment also values their careers. Segment three has the highest proportion of people earning an income in the highest bracket. Although this segment includes the highest proportion of retirees, many segment members are employed full time. Segment three members indicate the strongest desire to travel more, both for longer vacations and weekend getaways, with the highest optimal number of weekend getaways per year. This segment reports the highest QOL and the second highest rating of feeling good about life in general, and they report leading a meaningful and fulfilling life. Destination managers should find this segment the most attractive. These people value travel and they want to increase their level of vacations.

While all three segments indicated a high importance to the following motivators, Segment three is most motivated to try something new, experience an adventure, do exciting things, have fun and be entertained, gain social recognition, and get away from everyday life and routine. Vacations are vital to the existence of this segment. The Grevillea's stock in Table 1 illustrates this notion of core values, fundamental to the wellbeing and survival of the human (much like the Grevillea's stock nurtures the plant).

The evidence suggests the three segments value vacations differently. For Segment one, no amount of encouragement or promotion likely entices them to visit a destination, because they basically believe the trips do not contribute to their QOL. Segment two believes vacations enhance their QOL, but they may need to be reminded why travel is important to them. They may not need encouragement to take a vacation, but targeted promotional messages likely increases their frequency of travel. Segment three considers vacations to be a core QOL component. They desire for more travel. Destination management may focus on making Segment three loyal to their destination. 
Insignificant differences arose between the segments regarding several sociodemographic variables (e.g., gender, age, marital status, relationship status, having children), QOL domains (e.g., point allocation for the domains of family, people and money) as well as travel-related variables (e.g., optimal number of yearly vacations, and travel motives).

\section{Conclusions}

This paper proposes the Grevillea Model of the Importance of Vacations for Quality of Life, a dynamic, individual, and hierarchical model of the role vacations play in people's lives at any given point in time. The Grevillea Model's foundation is consistent with accepted psychological theories, such as Maslow's hierarchy of needs and the QOL concept. The proposed model offers a new perspective because the Grevillea Model: (1) is designed specifically for the QOL domain of Vacations, (2) acknowledges individual heterogeneity, and (3) acknowledges changes in domain importance over time within individuals.

Based on the Grevillea Model, a measurement tool enables respondents to classify 30 QOL domains. Respondents classify domains as important, or having the ability to further enhance, or as not important at all.

Vacations represent core QOL to 11 percent of the sample of Australian adults, and enhancement to 59 percent of respondents. Vacations do not contribute to the QOL of 30 percent of respondents. The segments differ significantly regarding background variables. Those who do not believe that vacations are important have an overall low QOL, and are lower income earners. People feeling vacations enhance their QOL tend to have a high overall QOL. Many members of Segment two would like to take more vacations and weekend getaways than they did in the last year. Travel motivations include: to escape from everyday life, to observe scenic beauty, and to experience something new. Finally, people perceiving vacations as a core aspect of their life tend to be high income earners who value 
their work. Interestingly, this segment contains the highest proportion of retirees-a segment of increasing attractiveness to the tourism industry (Boksberger and Laesser, 2009).

This study's findings have major implications for the tourism industry. The results suggest one-third of the market may not be suitable for target marketing. One-tenth of the market can be described as the core group of vacationers who are unlikely to sacrifice their vacations. Therefore, this group likely is crisis resistant, meaning that external events like global financial crises, terrorism fears, and medical pandemics may have less impact on their vacation plans than for people who perceive vacations simply as QOL enhancements. Still, crisis resistance should be studied in more detail in future. The largest segment, accounting for almost two-thirds of the sample, views vacations as enhancing their lives. This segment is well worth targeting through marketing. As opposed to those who see vacations as a core domain, the latter group also needs marketing communications to remind and motivate them about how vacations affect their QOL.

In summary, the Grevillea Model provides a useful framework for respondents to classify Quality of Life domains. The segmentation based on the Grevillea Model describes three very distinct a priori market segments. These segments differ in the importance they attribute to vacations as well as other socio-demographic and psychographic variables relevant for tourism marketing.

Like the native Australian Grevillea, the present study results are limited to a geographic location. Future work comparing people's classification of the Vacation domain both nationally (with a fully representative sample), and internationally, would be interesting. Although major differences compared to other developed countries are not expected to be observed, findings across the three a priori segments likely will be different in developing countries, where people's focus may lie on more fundamental needs (Sirgy et al., 1995). Collecting more background information on the three segments also would be of interest. 
Another interesting future study would be a longitudinal study monitoring how people's assessment of vacations changes over their lifetime. Longitudinal data enables researchers and practitioners to better understand the dynamic nature and importance of specific QOL domains. Finally, the current Grevillea Model does not consider that people have different motivations for travel. Future work should extend the Grevillea Model to other domains contributing to QOL as well as motivations to travel. 


\section{Acknowledgements}

We thank the Faculty of Commerce at the University of Wollongong for support though the internal grant schemes that enabled data collection for the present study.

\section{References}

Baloglu, S. \& McCleary, K. (1999). U.S. international pleasure travelers' images of four Mediterranean destinations: a comparison of visitors and nonvisitors. J. Trav. Res., $38(2), 144-152$.

Becken, S. \& Gnoth, J. (2004). Tourist consumption systems among overseas visitors: Reporting on American, German, and Australian visitors to New Zealand. Tour. Manag., 25(3), 375-385.

Bieger, T. \& Laesser, C. (2002). Market segmentation by motivation: The case of Switzerland. J. Trav. Res., 41(1), 68-76.

Bieger, T. \& Laesser, C. (2004). Information sources for travel decisions: toward a source process model. J. Trav. Res., 42(4), 357-371.

Bigne, J. \& Andreu, L. (2004). Emotions in segmentation: an empirical study. Ann. Tour. Res., 31(3), 682-696.

Boksberger, P. \& Laesser, C. (2009). Segmentation of the senior travel market by the means of travel motivations. Jour. Vac.Mark., 15(4), 311-322.

Campbell, A., Converse, P. \& Rodgers, W. (1976). The Quality of American Life. New York: Russell Sage.

Chen, J. (2003). Market segmentation by tourists' sentiments. Ann. Tour. Res., 30(1), 178193. 
Collins, D. \& Tisdell, C. (2002). Gender and differences in travel life cycles. J. Trav. Res., 41(2), 133-143.

Cummins, R., McCabe, M., Romeo, Y. \& Gullone, E. (1994). The comprehensive quality of life scale: Instrument development and psychometric evaluation on tertiary staff and students. Educ. Psychol. Meas., 54, 372-382.

Dalkey, N. \& Rouke, D. (1973). The Delphi procedure and rating quality of life factors. In: EPA, The Quality of Life Concept, II-209-II-221.Washington, DC: Environmental Protection Agency.

Dazord, A., Gerin, P. \& Boissel, J. (1994). Subjective Quality of Life assessment in therapeutic trials: Presentation of a new instrument in France (Subjective Quality of Life Profile: SQLP) and first results. In J. Orley \& W. Kuyken (Eds.), Measurement of Quality of Life in health care settings. Berlin, Heidelberg, New York: SpringerVerlag.

de Guzman, A., Leones, J., Tapia, K., Wong, W., \& de Castro, B. (2006). Segmenting motivation. Ann. Tour. Res., 33(3), 863-867.

Derek, G., Ron, J. \& Geraldine, P. (2009). Quality of Life. In: Dictionary of Human Geography, 5th ed., Oxford: Wiley-Blackwell.

Diener, E. \& Suh, E. (1997). Measuring quality of life: Economic, social, and subjective indicators. Soc. Ind. Res., 40, 189-216.

Dolnicar, S. (2008). Market segmentation in tourism. In: Dolnicar, S. (Ed.), Managing Tourism Firms, (pp. 152-162). Cheltenham: Edward Elgar Publishing.

Dolnicar, S. (2004). Beyond "commonsense segmentation": A systematics of segmentation approaches in tourism. J. Trav. Res., 42(3), 244-250. 
Dolnicar, S. \& Huybers, T. (2007). Different tourists - different perceptions of different places: Accounting for tourists' perceptual heterogeneity in destination image measurement. Tour. Anal., 12(5/6), 447-461.

Dolnicar, S. \& Lazarevski, K. (2009). Methodological reasons for the theory/practice divide in market segmentation. J.Mark. Manag., 25(3-4), 357-373.

Dolnicar, S. \& Leisch, F. (2004). Delivering the right tourist service to the right people: A comparison of segmentation approaches. In: Thyne, M. and Laws, E. (Eds.), Hospitality, Tourism, and Lifestyle Concepts: Implications for Quality Management and Customers Satisfaction, (pp. 189-207). Binghamton, NY: Haworth Hospitality Press.

Dunbar, G., Stoker, M., Hodges, T. \& Beaumont, G. (1992). The development of SBQOL - a unique scale for measuring quality of life. Brit. J. Med. Econ., 2, 65-74.

Ferrans, C. \& Powers, M. (1985). Quality of life index: Development and psychometric properties. Adv. Nurs. Sci., 8(1), 15-24.

Flanagan, J. (1978). A research approach to improving our quality of life. Amer. Psychol., $33(2), 138-147$.

Fodness, D. \& Murray, B. (1997). Tourist information search. Ann. Tour. Res., 24(3), 503523.

Frew, E. \& Shaw, R. (1999). The relationship between personality, gender, and tourism behavior. Tour. Manag., 20(2), 193-202.

Frisch, M. (1994). Quality of Life Inventory. Product Number 02104. Minneapolis, MN: National Computer Systems.

Frisch, M., Cornell, J., Villanueva, M. \& Retzlaff, P. (1992). Clinical validation of the quality of life inventory: A measure of life satisfaction for use in treatment planning and outcome assessment. Psychol. Assess., 4(1), 92-101. 
Frochot, I. (2005). A benefit segmentation of tourists in rural areas: A Scottish perspective. Tour. Manag., 26(3), 335-346.

Gall, T., \& Evans, D. (2000). Preretirement expectations and the quality of life of male retirees in later retirement. Canad. J. Behav. Sci., 32(3), 187-197.

Gilbert, D. \& Abdullah, J. (2004). Holiday taking and the sense of well-being. Ann. Tour. Res., 31(1), 103-121.

Goldsmith, R. \& Litvin, S. (1999). Heavy users of travel agents: A segmentation analysis of vacation travelers. J. Trav. Res., 38(2), 127-133.

Gratton, L. (1980). Analysis of Maslow's Need Hierarchy with three social class groups. Soc. Indic. Res., 7, 463-476.

Greengold Garden Concepts (2006). Care and Maintenance Notes: Grevilleas. Available at: http://www.greengold.com.au/greengold/CARENOTES/CARENOTES/greville.htm, (accessed 8 March 2010).

Haas, B. (1999). Clarification and integration of similar quality of life concepts. J. Nurs. Scholar., 31(3), 215-220.

Hsu, C. \& Crotts, J. (2006) Segmenting mainland Chinese residents based on experience, intention and desire to visit Hong Kong. Int. J. Tour. Res., 8(4), 279-287.

Javalgi, R., Thomas, E. \& Rao, S. (1992). Consumer behavior in the US pleasure travel marketplace: An analysis of senior and non-senior travelers. J. Trav. Res., 31(2), 1419.

Johnston, D. (1988). Toward a comprehensive "quality of life" index. Soc. Ind. Res., 20, 473496.

Juaneda, C. \& Sastre, F. (1999). Balearic Islands tourism: A case study in demographic segmentation. Tour. Manag., 20(4), 549-552. 
Keith, K. (2001). International quality of life: Current conceptual, measurement, and implementation issues. In: Glidden, Laraine, Masters (Eds.) International Review of Research in Mental Retardation 24, (pp. 49). San Diego: Academic Press.

Kerlinger, F. (1973). Foundations of Behavioral Research ( $2^{\text {nd }}$ ed.). New York: Holt, Rinehart \& Winston.

Kim, D., Lehto, X. \& Morrison, A. (2007). Gender differences in online travel information search: Implications for marketing communications on the internet. Tour. Manag., $28(2), 423-433$.

Kotler, P., Armstrong, G., Brown, L. \& Adam, S. (1998). Marketing (4 ${ }^{\text {th }}$ ed.). Australia: Prentice Hall, Pearson Education.

Kreitler, S. \& Kreitler, M. (2006). Multidimensional quality of life: A new measure of quality of life in adults. Soc. Indic. Res., 76(1), 5-33.

Lance, C., Mallard, A. \& Michalos, A. (1995). Tests of the causal directions of global-life facet satisfaction relationships. Soc. Ind. Res., 34, 69-92.

Lazim, M. \& Osman, M. (2009). A new Malaysian quality of life index based on fuzzy sets and hierarchical needs. Soc. Ind. Res., 94(3), 499-508.

Lee, D. \& Sirgy, M. (1995). Determinants of involvement in the consumer/ marketing life domain in relation to quality of life: a theoretical model and research agenda. In: Meadow, H., Sirgy, M. \& Rahtz, D. (Eds.), Development in Quality of Life Studies in Marketing, (pp. 13-18). Dekalb, IL: Academy of Marketing Science.

Lee, S. \& Tideswell, C. (2005). Understanding attitudes towards leisure travel and the constraints faced by senior Koreans. J. Vac. Mark., 11(3), 249-263.

Leisen, B. (2001). Image segmentation: The case of a tourism destination. J. Serv. Mark., 15(1), 49-66. 
Lever, J. (2000). The development of an instrument to measure quality of life in Mexico city. Soc. Ind. Res., 50, 187-208.

Maslow, A. (1962). Toward a Psychology of Being. Princeton, NJ: Van Nostrand.

Mazanec, J. (2000). Market Segmentation. In: Jafari, J. (Ed.), Encyclopedia of Tourism. London: Routledge.

Molera, L. \& Albaladejo, I. (2007). Profiling segments of tourists in rural areas of SouthEastern Spain. Tour. Manag., 28(3), 757-767.

Muller, T. (1991). Using personal values to define segments in an international tourism market. Int. Mark. Rev., 8(1), 57-70.

Murray, H. (1938). Explorations in Personality. New York: Oxford University Press.

Myers, J. \& Tauber, E. (1977). Market Structure Analysis. Chicago: Amer. Marketing Association.

Neal, J., Sirgy, M. \& Uysal, M. (1999). The role of satisfaction with leisure travel/tourism services and expenditure in satisfaction with leisure life and overall life. J. Bus. Res., $44,153-163$.

Neal, J., Sirgy, M. \& Uysal, M. (2004). Measuring the effect of tourism services on travellers' Quality of Life: Further validation. Soc. Indic. Res., 69, 243-277.

Olson, D. \& Barnes, H. (1992). Quality of Life Scale. In: D. Olson, H. McCubbin, H. Barnes, A. Larsen, M. Muxen, \& M. Wilson (Eds.), Family Inventories (3rd ed.; pp. 55-67). Minneapolis, MN: Life Innovations.

Pizam, A. \& Calantone, R. (1987). Beyond psychographics - values as determinants of tourist behavior. Int. J. Hosp. Manag., 6(3), 177-181.

Rajeski, W. \& Mihalko S. (2001). Physical activity and quality of life in older adults. $J$. Gerontol., Series A: Biol. Sci., 56A, 23-36. 
Reid, L. \& Reid, S. (1997) Traveler geographic origin and market segmentation for small island nations: the Barbados case. J. Trav. Tour. Mark., 6(3), 5-21.

Richards, G. (1999). Vacations and the quality of life: Patterns and structures. J. Bus. Res., 44, 189-198.

Rubenstein, C. (1980). Vacations: Expectations, satisfactions, frustrations, fantasies. Psychol. Today, 14, 62-76.

Ryff, C. \& Keyes, C. (1995). The structure of psychological well-being revisited. J. Pers.Soc. Psychol., 69, 719-727.

Sarigollu, E. \& Huang, R. (2005). Benefits segmentation of visitors to Latin America. $J$. Trav. Res., 43(3), 277-293.

Scalon, T. (1993). Value, desire, and Quality of Life. In: M. Nussbaum \& A. Sen (Eds.), The Quality of Life. New York: Oxford University Press Inc.

Shoemaker, S. (2000). Segmenting the mature market: 10 years later. J. Trav. Res., 39(1), 1126.

Sirakaya, E. \& Woodside, A. (2005). Building and testing theories of decision making by travelers. Tour. Manag., 26(6), 815-832.

Sirgy, M. (2010). Toward a Quality-of-Life theory of leisure travel satisfaction. J.Trav. Res., 49(2), 246-260.

Sirgy, M., Cole, D., Kosenko, R., Meadow, H., Rahtz, D., Cicic, M., et al. (1995). developing a life satisfaction measure based on need hierarchy theory. In: J. Sirgy \& A. Samli (Eds.), New Dimensions in Marketing/Quality of Life Research. Westport, CT: Quorum Books.

Sirgy, M., Kruger, P., Lee, D., Yu, G. (2010). How does a travel trip affect tourists’ life satisfaction? J. Trav. Res., (in press). 
Sung, H. (2004). Classification of adventure travelers: behavior, decision making, and target markets. J. Trav. Res., 42(4), 343-356.

Taylor, A. \& Prideaux, B. (2008). Profiling four wheel drive tourism markets for desert Australia. J. Vac. Mark., 14(1), 71-86.

Todd, S. (2001). Self-concept: A tourism application. J. Cons. Behav., 1(2), 184-196. 
TABLE 1:

Segment profiles attributing different levels of importance to vacations

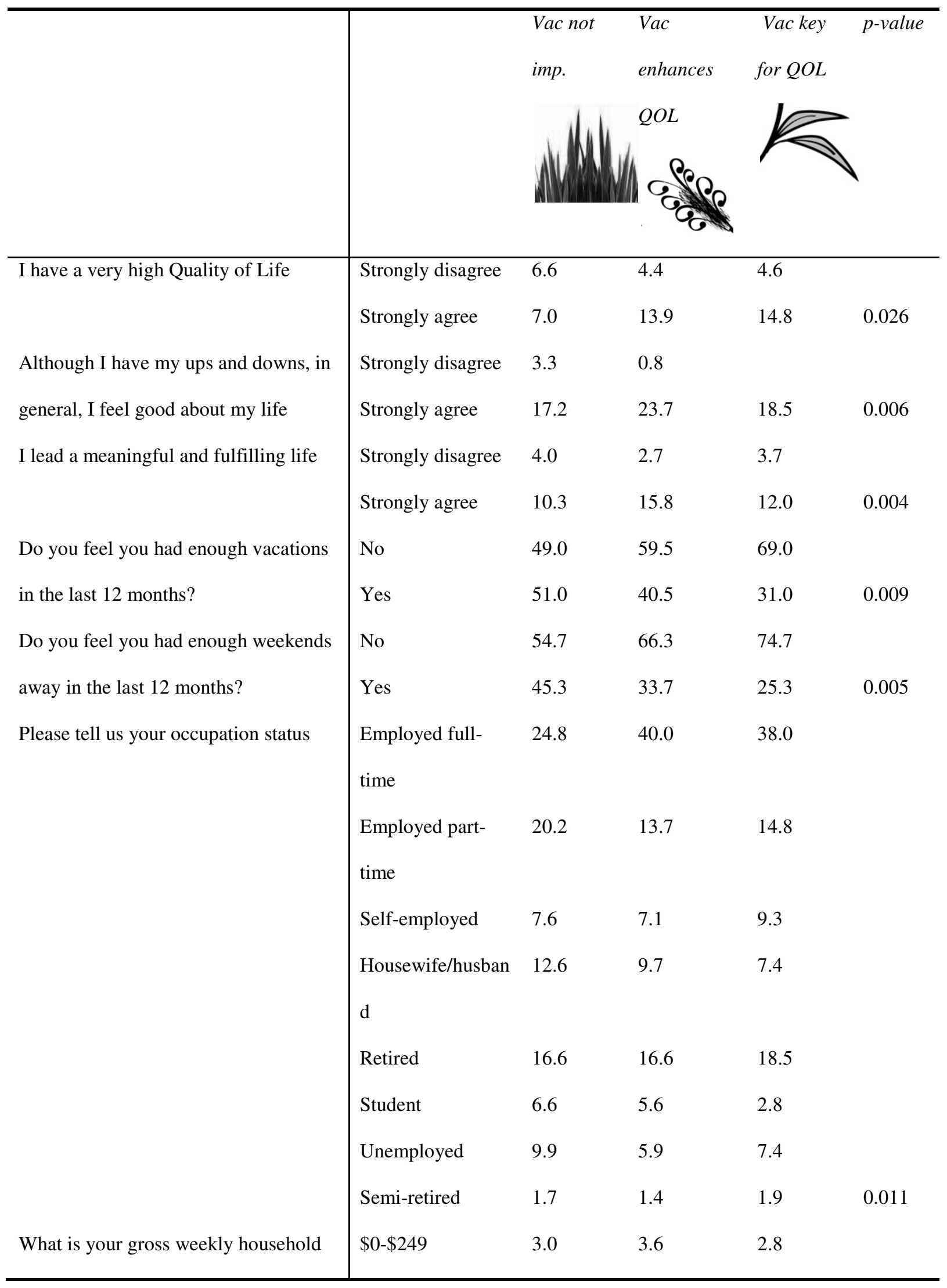




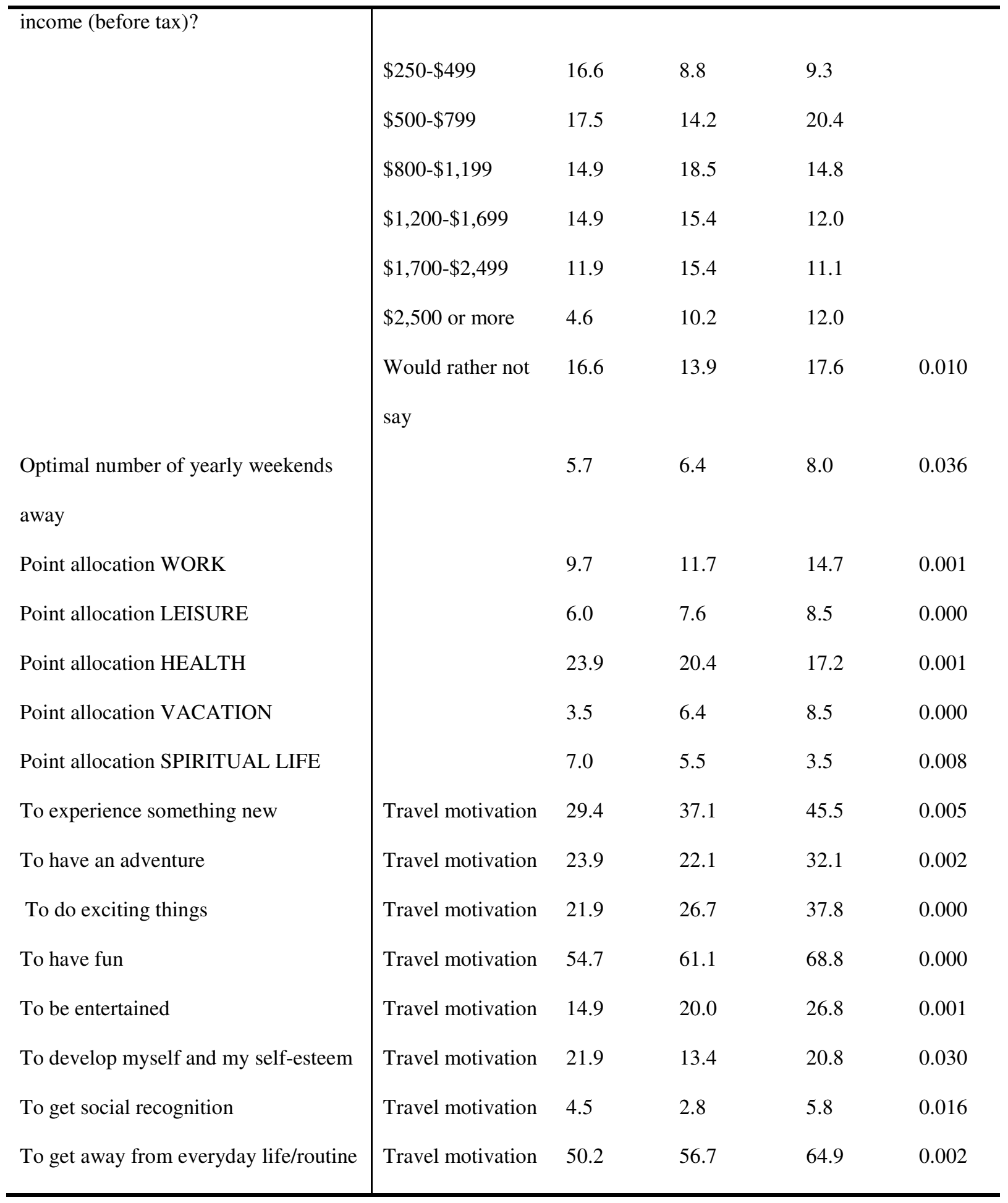




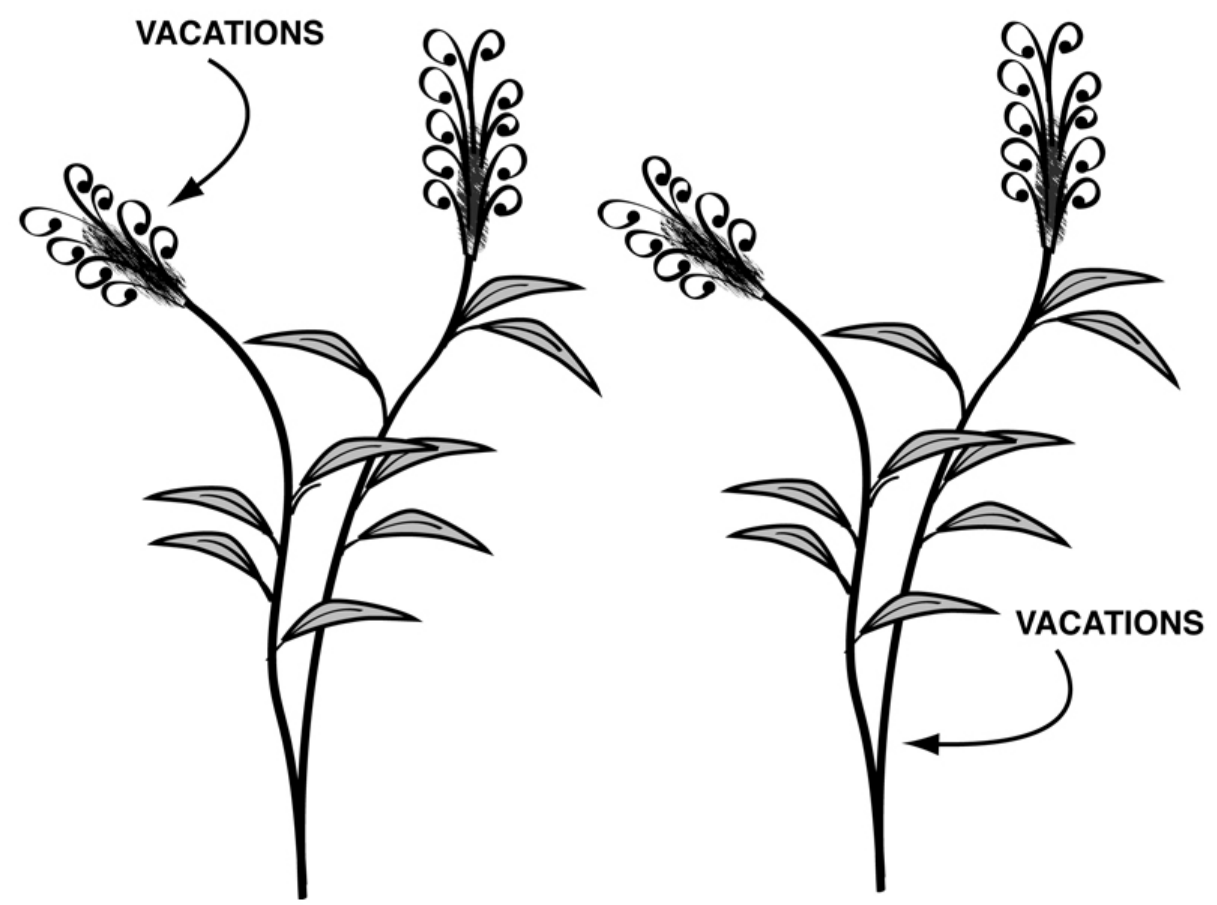

Figure 1.

The Grevillea model of the importance of vacations for quality of life 